\title{
THE IMPORTANCE OF OPPORTUNITY RECOGNITION BEHAVIOUR AND MOTIVATORS OF EMPLOYEES WHEN ENGAGED IN CORPORATE ENTREPRENEURSHIP
}

\author{
Boris URBAN $^{1}$, Eric WOOD ${ }^{2}$ \\ Graduate School of Business, University of Witwatersrand, \\ 2 Davids st Parktown, Johannesburg, South Africa \\ E-mails: 1'boris.urban@wits.ac.za (correspondingauthor); 2ericwood@wits.ac.za \\ Received 25 February 2013; accepted 22 April 2013
}

\begin{abstract}
Organisational innovation depends on individuals and managers fostering and maintaining the innovative capacities of the firm, where opportunity recognition is important for promoting corporate entrepreneurship. The study is unique in its focus on understanding opportunity recognition behaviours and motivators of employees and how these perceptions may influence corporate entrepreneurial activity. The study is conducted in an under-researched emerging market context, where 187 respondents were surveyed in the financial sector industry. The empirical findings indicate that employees perceive themselves as having high levels of opportunity recognition behaviours and motivators which are positively associated with willingness to engage in corporate entrepreneurial initiatives. The results further show that there is a significant positive relationship between opportunity recognition behaviours and the frequency of opportunities recognised. Implications highlight the importance of fostering opportunity recognition behaviours within an organisation and motivating employees to act innovatively.
\end{abstract}

Keywords: firm innovation, opportunity recognition, corporate entrepreneurship, motivations, willingness, financial sector, South Africa.

JEL Classification: L26, M19.

\section{Introduction}

Organizations are continually seeking to re-orientate themselves to become strategically innovative where previous literature and empirical findings point to corporate innovation as an important element in organizational renewal and economic development (Ucbasaran et al. 2009). Since innovation is essential for economic development, a theory of economic development requires not simply a theory of the firm but a theory of the innovating firm (Lazonick 2008). It is through the interaction of the innovative enterprise and the developmental state that entrepreneurial activity inserts itself into the economic system to contribute to the process of economic development (Bosma et al. 2010). Innovation in corporations has been labelled in many different ways, with conceptual roots in innovation entrepreneurship (Schumpeter 1934) and innovation management (Drucker 1979). More recent terms include intrapreneurship 
(Antoncic, Hisrich 2001), venture entrepreneurship (Tang, Koveos 2004), corporate intrapreneurship (Dess et al. 2003), strategic entrepreneurial posture (Covin, Slevin 1989), and internal corporate venturing (Hornsby et al. 2002); these not being merely differences in nomenclature, but each having specific meaning and focus. Corporate entrepreneurship (CE) as a construct which we adopt in this paper includes strategic renewal (organizational renewal involving major strategic and / or structural changes), innovation (the introduction of something new to the marketplace), and corporate venturing (corporate entrepreneurial efforts that lead to the creation of new companies within the corporate company), are all important and legitimate parts of the CE process (Morris, Kuratko 2002; Urban 2009).

$\mathrm{CE}$ is typically modelled as a learning process in which firms alternately engage in exploration followed by the exploitation of resulting opportunities (Phan et al. 2009). It is widely accepted that the innovation process has attitudinal and behavioural components (Roupas 2008; Urban 2009), with the opportunity recognition process representing one of the core intellectual questions in the domain of corporate innovation and entrepreneurship (Urban 2013).. Improved understanding of opportunity recognition helps in identifying crucial aspects necessary for cultivating entrepreneurial ventures, thereby contributing to economic growth and social development (Goedhuys, Sleuwaegen 2010; Ucbasaran et al. 2009).

One major characteristic of firms in emerging markets is that established firms are being transformed into market-oriented enterprises. As the economy is becoming more market-based, it is necessary for these reformed enterprises to undergo an entrepreneurial transformation at the organizational level in order to adapt to the transitioning institutional environment and maintain competitiveness in both local and global markets (Hoskisson et al. 2000; Peng 2003; Urban 2013).

This study builds on existing conceptualisations of innovative opportunities (Holmen et al. 2007: 37), which are defined as "the possibility to realise a potential economic value inherent in a new combination of resources and market needs, emerging from changes in the scientific or technological knowledge base, customer preferences, or the interrelationships between economic actors". Opportunities establish the foundation of sustainable entrepreneurship thus enabling entrepreneurial rents while simultaneously improving local and global as well as social and environmental conditions (Cohen, Winn 2007). Despite that no agreement has been reached on whether opportunities are identified, recognized or created, it has been argued that the opportunity identification process begins when alert (corporate) entrepreneurs notice factors in their domain of expertise that result in the recognition and evaluation of potential business opportunities (Ardichvili et al. 2003). This article makes a contribution to the literature by focusing on opportunity recognition behaviour in terms of both frequency and importance, and provides links to entrepreneurial behaviours and motivators that employees' exhibit in order to promote entrepreneurship in organizations (Monsen et al. 2010).

Past research demonstrates the importance of motivators, such as human and organisational factors, to increase work performance and inclination towards firm innovation (Dysvik, Kuvaas 2011; Morrison et al. 2005). Drawing on innovative opportunity and 
opportunity-based conceptualizations of entrepreneurship, which emphasize the heterogeneity in identification and exploitation of opportunities, the key research question of this article is to determine if perceptions of a supportive corporate environment lead to increased opportunity recognition and motivation. While entrepreneurial behaviour on the part of individuals is neither controllable nor predictable, it can be fostered and facilitated (Morris et al. 2009). The more employees perceive they are receiving support from the organisation, the more they might be expected to feel a sense of obligation and be inclined to reciprocate in both attitudinal and behavioural ways (Dimov 2007).

Although, CE has been emphasized as the key for emerging economy firms to revitalize, reconfigure resources, and transform into market-orientated firms that are ready to compete in the global economy, thus far, there has not been much work on CE in emerging markets, as contrasted to entrepreneurship studies at the individual level (Yiu, Lau 2008). Recognizing that innovative actions are the bedrock of entrepreneurial processes and behaviour for both large and SMEs Urban 2013), and that these behaviours may be critical to the long term vitality of an economy, it is important to facilitate the empirical study of them in an under researched, emerging market environment (Bruton et al. 2008). It has been shown in other domains, such as strategy, that researchers should not assume that findings in a developed economy will be equally applicable to an emerging economy (Peng 2003). The study takes place in South Africa which remains a highly significant regional political and economic player in sub-Saharan Africa (SSA), and has recently joined the BRIC (Brazil, Russia, India, and China) countries (Carmody 2012). It is anticipated that the study will allow researchers to compare and examine $\mathrm{CE}$ in terms of opportunity recognition behaviour and motivators in similar environmental contexts. The rest of the article is structured as follows. First relevant theoretical foundations are accessed to provide a basis for the hypotheses. Next the research approach is delineated in terms of the sample and measuring instruments. This is followed by highlighting the specific analytic methods best suited to test the hypotheses. Results and implications are then discussed in an emerging market context, and the study's limitations are addressed with future research suggested.

\section{Theory and hypotheses}

At the level of the business enterprise, the collective character of the innovation process reflects the reliance of the entrepreneur on the skills and efforts of other enterprise participants in the exercise of strategic control, the management of organizational integration, and the mobilization of financial commitment (Morris, Kuratko 2002). Consequently, $\mathrm{CE}$, as an internal organizational transformation and resource configuration mechanism, is a very important mediator that determines whether firms can realize the benefits derived from different resources and capital (Yiu, Lau 2008). A longstanding literature has conceptualized $\mathrm{CE}$ as a multidimensional phenomenon that incorporates the behaviour and interactions of the individual, organizational, and environmental elements within organizations (Dess et al. 1999; Kuratko et al. 1993; Zahra 1993). In recent years, CE has been the focus of considerable research activity (Covin, Kuratko 2008; Ireland et al. 2009; Phan et al. 2009), and with the scope of CE 
widening, organizations lacking prior entrepreneurial recognition are adopting CE in order to survive and succeed in increasingly competitive and financially constrained environments (Kuratko, Audretsch 2009; Neill, York 2011). Top-level managers are responsible for putting into place pro-entrepreneurship organizational architecture, that is where the workplace exhibits structural, cultural, resource, and system attributes that encourage entrepreneurial behaviour, both individually and collectively (Morris et al. 2009).

A synthesis of the main studies on CE indicates that several attributes promote entrepreneurial action but to some extent these studies ignore individual participation as well as different groups, which may promote CE within organizations (Ireland et al. 2009). Organizations pursuing CE strategies are likely to exhibit a cascading, yet integrated, set of entrepreneurial actions at the senior, middle, and first-levels of management, with managers across levels sharing joint responsibility for their organization's entrepreneurial actions (Hornsby et al. 2009; Santangelo, Pini 2011). The combination of knowledge, skills and judgements of interested and committed employees and managers (Allen et al. 1997) often ensures the success of CE initiatives (Poon et al. 2006).

Scholars in the field of innovation and management have long been interested in understanding the nexus between opportunities and entrepreneurs and have published a wide variety of answers. These theories range from a micro-economic explanation, employing the standard utility maximization framework (Douglas, Shepherd 2002) to the immutable personal attributes explanation (Lee, Venkataraman 2006). Research on opportunity recognition remains a fundamental area of focus, but prior research has focussed primarily on the entrepreneur or the team of entrepreneurs operating within their own ventures (Ireland, Webb 2007), rather than in a corporate context. However, the success of any firm hinges on the ability of employees to recognise opportunities, which incorporates opportunity identification and development and is best executed as a cyclical and iterative process (Ardichvili et al. 2003). This leads to the first hypothesis, where it is anticipated that:

H1: Opportunity recognition behaviours play a significant role in identifying CE initiatives.

Firms depend on the willing engagement of employees to lend their efforts to CE projects (Monsen et al. 2010). One of the major elements in developing CE organisational initiatives is the appropriate use of motivators and rewards (Hornsby et al. 2002; Ireland et al. 2009). Personality differences and intrinsic motivation are likely to affect the persistence to pursue an idea or opportunity, the likelihood to abandon the beliefs in the idea, and the desire and ability to discuss and defend the idea in a broader social context (Dimov 2007). However, even if an individual is motivated to recognise opportunities, the act of opportunity recognition is unlikely unless he or she has the prior knowledge to do so. Cognitive frameworks, pattern recognition and entrepreneurial alertness may be influenced by the entrepreneur's prior experience, and prior experience may not be a positive influence on opportunity recognition (Zahra et al. 2005). Recognising that opportunity recognition is best viewed as a multi-stage phenomenon that is influenced by numerous motivators and factors (Lumpkin et al. 2004), it is hypothesised that. 
H2: Opportunity recognition motivators play a significant role in identifying CE initiatives.

If employees cannot see a clear link between effort and performance, and between performance and reward, they may remain unwilling to participate in $\mathrm{CE}$ initiatives $(\mathrm{Ku}-$ ratko, Audretsch 2009). Research further demonstrates that when individuals perceive alignment between an opportunity's means of supply and target market, the more they perceive this opportunity as generally feasible and generally desirable (Gregoire et al. 2010). Additionally, most models of opportunity recognition emphasize the importance of frequency of opportunities recognised and the probability of pursuing further opportunities (Ardichvili et al. 2003; Timmons 2008). Drawing on the above research and findings, which emphasize the role of perceived opportunity attractiveness and motivation when recognising opportunities, the third and fourth hypotheses relate directly to understanding the importance and frequency of opportunities (low, medium, high) recognised in relation to corporate entrepreneurship initiatives.

H3: The higher the frequency of opportunities recognised the greater the perceived importance of CE initiatives.

H4: The higher the level of opportunity recognition motivators the greater the perceived importance of CE initiatives.

In order to inject entrepreneurship into organizations which is sustainable, it is contingent that individual members undertake innovative activities, which stimulate positive perceptions in executive management, which in turn leads to further allocation of necessary organizational support and resources (Kuratko, Audretsch 2009). Typically evaluations of opportunity attractiveness are made in terms of potential competitive advantage and returns, and where the evaluation is future focused in terms of success if the opportunity were exploited (Lee, Venkataraman 2006). Under these circumstances, participants can sense if management is not sincere in its commitment to the CE initiative or if the required resources are unavailable to take the initiative through to success (Allen et al. 1997).

Building on the above hypotheses, it is further proposed that the perceived success of the CE initiative will act as a moderator between the frequency and perceived importance of opportunities recognised and motivators.

H5: The perceived success of the CE initiative moderates the relationship between

(a) frequency of opportunity recognition behaviours, and (b) perceptions of the importance of opportunity recognition motivators.

\section{Methodology}

\subsection{Data collection}

Data was collected from respondents in a single industry who met pre-determined selection criteria. By focusing on a single industry sector, a greater homogeneity of context is achieved which addresses the concerns of broad applicability versus perfect suitability for narrower groups (Davidsson 2004). Consequently the focus is on a single 
industry - financial services. The sample frame of participating financial services firms was structured using the Johannesburg Chamber of Commerce and Industry (2008) listing and the Financial Services Board (Financial Services Board 2011) with a list of approved financial services companies and contactable asset managers. Participants in firms were selected on the basis that its principal business should be in one of the four defining categories as defined by The Financial Sector Charter on Black Economic Empowerment, (Government Gazette 2007): banking, insurance, brokerage firms (including financial services providers as regulated by the financial services board), asset managers and collective investment schemes. Based on this sampling frame 425 employees and managers across the industry ranging from CEOs, company secretaries, middle managers, sales staff and brokers were surveyed. As CE refers to an individual self-perception of a firm's entrepreneurial activities and orientation, their self-perception will be closely related to the behaviour of the firm (Wiklund 1999). Consistent with previous studies (Urban 2013) control variables included, firm age and firm size. A single contact person within each company was established, where this person then provided the e-mail details of other willing and qualified participants. The total response rate achieved was $46 \%$, and a final sample of 195 respondents, from 23 companies was obtained, where approximately a third of the firms (31\%) were drawn from the banking sector, $25 \%$ from asset management, $25 \%$ from the Insurance sector, and $18 \%$ from brokerage firms. To test for non-response bias (Armstrong, Overton 1977), firm size, age and sales growth were compared with non-responding firms by using secondary data obtained from the same Johannesburg Chamber of Commerce and Industry (2008) listing. Results of t-tests comparing these firms with the current study sample's mean scores on the variables revealed no differences $(\mathrm{p}>0.10)$, suggesting that the sample appears to be representative of the population from which it is based, on these firm attributes.

Sampling characteristics indicate that almost two-thirds $(65 \%)$ of the respondents have spent more than 10 years in their current careers and half $(51 \%)$ of respondents have been employed by their current employer for more than four years. In terms of firm size, approximately three quarters (74\%) of the firms employ in excess of 200 employees, while for firm age, the majority of firms $(68 \%)$ had been in existence for more than 10 years, while $11 \%$ had been in existence for less than 5 years.

\subsection{Measures}

Questionnaire items were based on prior studies, where research has focused on opportunity recognition behaviours (13 items), motivators (11 items) and CE practices (5 items) (Kaish, Gilad 1991; Morris et al. 2009; Urban 2009). The questions were formulated to measure perception, which is widely used in CE studies (Antoncic, Hisrich 2004). Measures were based on constructs of opportunity recognition, number of opportunities pursued, and perceptions of managerial support and financial reward for corporate entrepreneurial activities. Metric (i.e. interval and ratio scaled) data were measured on a 1 to 7 Likert scale, where ' 1 ' = strongly agree and ' 7 ' = strongly disagree.

The instrument was broken down into the following three sections: Opportunity recog- 
nition behaviours (includes frequency of opportunity recognition behaviours); (2) Opportunity recognition motivators; (3) Alignment of opportunity recognition behaviours to $\mathrm{CE}$ initiatives. The first section items for opportunity recognition behaviour (OPR) were adapted from the Panel Study of Entrepreneurial Dynamics (PSED) survey (Hills et al. 1999), where it is recognised that OPR is highly complex, influenced by a variety of factors, e.g. human capital and networking and included questions such as "I am able to spot opportunities more quickly than others". Most models of OPR emphasize the frequency and importance of perceptions in opportunity recognition, and subsequently variables for the OPR are consistent with established conceptual frameworks discussed earlier in the literature review and include items on experience, learning and the creativity process. Next, recalling from literature the role of perceived opportunity attractiveness and motivation when recognising opportunities, items for opportunity recognition motivators (OPM) included both financial and non-financial motivators, and included questions such as "If I recommend a successful opportunity I will be financially rewarded" (Shane et al. 2003; Zahra et al. 2005). The last section used existing formulations to ascertain perceptions of CE initiatives ( 5 items), where items included alignment of OPR to corporate strategy, managerial support and financial rewards, and included questions such as "I aim to identify opportunities that are aligned to company strategy" (Hornsby et al. 2009).

\subsection{Data analysis}

In order to ensure the overall instrument had face and content validity, a preliminary analysis via a pilot test was undertaken. Based on respondent feedback, several items were reverse scaled to avoid ambiguity. This procedure ensured that the respondents had no difficulties in answering the questions and there was no problem in recording the data. The measures had been previously subjected to principal components factor analysis, with satisfactory results in terms of factor loadings (Urban 2009). Nonetheless, all scales were tested for reliability for this sample of respondents. Cronbach Alphas for the different scales are: $\mathrm{OPR}=0.83 ; \mathrm{OPM}=0.72 ; \mathrm{CE}$ alignment $=0.70$, indicating adequate internal consistency in these measures (Cooper, Emory 1995).

Common method response bias was controlled for by safeguarding respondent anonymity, as well as ensuring that the questions relating to the dependent variables were located away from the independent and control variables in the instrument. Furthermore, all items relating to independent, dependent and control variables were explored in a single principal component analysis (PCA), using Harman's one-factor test (Podsakoff et al. 2003) to check if one component accounted for most of the variance. Six components with eigenvalues greater than 1.0 were detected, which accounted for $63 \%$ of the variance. The largest component accounted for only $11.44 \%$ of the total variance, and consequently no evidence of common method bias was identified.

The basic regression model (1) without the interaction effect as well as that with the interaction effect was formulated as:

$$
\text { Freq Opportunity_recognition }_{\text {_t }}=\alpha+\beta\left(\text { Percep }_{\text {Motivators }}\right)+\delta\left(\text { Percep }_{\text {Behaviours }}\right) \text {. }
$$


R-square from the above regression (1) was compared with the R-square to be obtained from the regression equation below (2). If the R-square from equation (2) was higher than the one from equation (1) and was positive and statistically significant, then one can conclude that success moderates the impact of perceptions on entrepreneurial opportunity recognition:

Freq Opportunity_recognition $=\infty+\beta\left(\right.$ Percep $\left._{\text {Motivators }}\right)+\delta\left(\right.$ Percep $\left._{\text {Behaviors }}\right)+\gamma($ Success $)$.

\section{Results}

To test hypothesis 1 where it was anticipated that OPR plays a significant role in identifying CE initiatives, the mean of the OPR items were calculated as 5.44, indicating a relatively high score. An analysis of the range of results given a $95 \%$ confidence shows a lower limit of 5.32 which is also considered high. A single sample t-test was run and the significance of the t-test result was interpreted as a significant positive response in terms of OPR: $\mathrm{t}(187)=23.01, p<0.001$, providing support for hypothesis 1 .

The same procedure was used to test hypothesis 2 where OPM was proposed to play a significant role in identifying CE initiatives. A single sample t-test was run and the significance of the t-test result was interpreted as a significant positive response with respect to OPM: $\mathrm{t}(187)=21.08, p<0.001$, providing support for hypothesis 2 .

Hypothesis 3 purported that the higher the frequency of opportunities recognised the greater the perceived importance of CE initiatives. The frequency of OPR was structured on five measurements: (1) 1 only; (2) $2-4$; (3) 5 - 10; (4) 11 or more. These classifications were initially derived from simple counts based on open responses and then consolidated into three categories of opportunities recognised, identified as either low, medium or high; see Table 1 for the comparison of the OPR means scores with the frequency of opportunities recognised in terms of these three categories.

An examination of the significance of the results using a one-way ANOVA F-test revealed that the OPR mean scores were statistically different across the opportunity recognition frequency categories: $\mathrm{F}(4.182)=8.115, p<0.05$. Additionally, the Scheffe post-hoc test results show a pattern of monotonic increase, where the mean of respondents who identified no opportunities is not significantly different from the mean of those respondents who identified a low number of opportunities. However, the means of those respondents who identified a medium and high number of opportunities are

Table 1. Comparison of OPR means by frequency of opportunities recognised

\begin{tabular}{lccccc}
\hline \multicolumn{7}{c}{ Breakdown table of descriptive statistics N $=187$} \\
\hline $\begin{array}{l}\text { How many opportunities have you } \\
\text { identified for your current company? }\end{array}$ & $\begin{array}{c}\text { OPR } \\
\text { mean }\end{array}$ & $\begin{array}{c}\text { Confidence } \\
95.000 \%\end{array}$ & $\begin{array}{c}\text { Confidence } \\
95.000 \%\end{array}$ & $\begin{array}{c}\text { Number of } \\
\text { OPR }\end{array}$ & $\begin{array}{c}\text { Std. } \\
\text { dev. }\end{array}$ \\
\hline Low & 5.52 & 5.12 & 5.91 & 12 & 0.62 \\
\hline Medium & 5.67 & 5.40 & 5.93 & 34 & 0.77 \\
\hline High & 5.73 & 5.57 & 5.90 & 41 & 0.52 \\
\hline All Groups & 5.44 & 5.32 & 5.56 & 187 & 0.86 \\
\hline
\end{tabular}


significantly higher than for those who identified a low number of opportunities. These results provide support for hypothesis 3 .

For hypothesis 4 , the same procedure was used to test if higher levels of OPM were associated with greater perceived importance of CE initiatives. An analysis of the significance of the results provides support for the hypothesis: $\mathrm{F}(4.182)=0.774, p<0.05$. In order to evaluate the moderation effect, a new interaction variable was created (the focal independent variable multiplied by the moderator variable). However in order to deal with the possibility of multicollinearity the independent variables were centred with reference to their averages. The newly created interaction variable was used to express the strength of the moderator effect of perceived success on CE initiatives. The regression output of the base model (frequency of opportunity recognition versus OPR behaviours), plus the effect of the moderator (success) and the interaction variable (OPR behaviour * success) is reflected in Table 2 . Although control variables were included in the equation they are not displayed since the variables of firm age and firm size produced non-significant coefficients with the dependent variable.

Table 2. Moderation effect of CE success on the relationship between frequency of opportunities recognised and opportunity recognition behaviours

\begin{tabular}{lcccccc}
\hline & Base model & \multicolumn{3}{c}{ Including moderator } \\
\hline Intercept & $\mathrm{B}$ & $\mathrm{SE}$ & $\mathrm{b}$ & $\mathrm{B}$ & $\mathrm{SE}$ & $\mathrm{b}$ \\
\hline OPR behaviours & $3.2506^{* * *}$ & 0.0507 & .00 & $3.3071^{* * *}$ & 0.0519 & .00 \\
\hline Success & $0.3017^{* * *}$ & 0.0616 & .19 & $0.2228^{* * *}$ & 0.0640 & .14 \\
\hline Behaviours $\times$ success & 0.7882 & 0.0399 & .78 & $0.7891^{* * *}$ & 0.7126 & .78 \\
\hline $\mathrm{R}^{2}$ & 0.73 & & $-0.1760^{* * *}$ & 0.0509 & -.14 \\
\hline$\Delta \mathrm{R}^{2}$ & - & & 0.75 & \\
\hline $\mathrm{F}$ & $254.55^{* * *}$ & & $0.016^{* * *}$ \\
\hline
\end{tabular}

Notes: $\mathrm{B}=$ unstandardized coefficients; $\mathrm{SE}=$ standard errors; $\beta=$ standardised coefficients; $N=187$; ${ }^{* * *}=\mathrm{p}<.01 ;{ }^{* *}=p<.05 ;{ }^{*}=p<.10$.

In Table 2, the interaction term (OPR behaviours $\mathrm{x}$ Success) has an unstandardized slope of $\mathrm{B}=-0.176$, where the entire confidence interval $(95 \%)$ lies above zero and $p<0.05$ in all instances, indicating statistical significance at the $5 \%$ level. The $\Delta \mathrm{R}^{2}$ from the base model to the model including the moderator is 0.02 which indicates the interaction effect.

The interaction effect of the moderator has been plotted graphically and is represented in Figure 1, where respondents are likely to recognise a higher number of opportunities as more opportunities are successfully implemented. Respondents who have a low or medium number of successfully implemented opportunities, the total number of opportunities recognised increases as OPR increases. Those respondents who have a high number of successfully implemented opportunities tend to show a slight decrease in the total number of opportunities identified as OPR increases. 


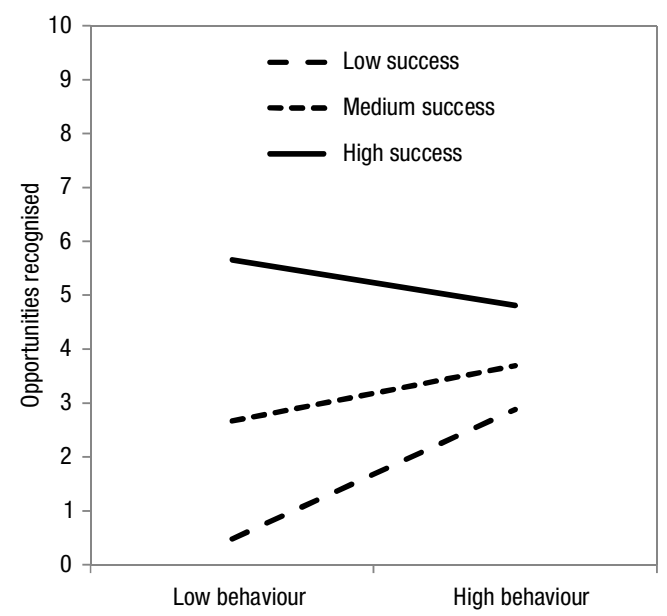

Fig. 1. Interaction effect of CE success and frequency of opportunities recognised

Table 3. Moderation effect of CE success on the relationship between frequency of opportunities recognised and opportunity recognition motivators

\begin{tabular}{lcccccc}
\hline & \multicolumn{2}{c}{ Base model } & \multicolumn{3}{c}{ Including moderator } \\
\hline & $\mathrm{B}$ & $\mathrm{SE}$ & $\mathrm{b}$ & $\mathrm{B}$ & $\mathrm{SE}$ & $\mathrm{b}$ \\
\hline Intercept & $3.2537^{* * *}$ & 0.0538 & .00 & $3.2548^{* * *}$ & 0.0536 & .00 \\
\hline Motivators & $0.0529^{* * * * *}$ & 0.0540 & .04 & $0.0787^{* * * * *}$ & 0.0564 & .06 \\
\hline Success & 0.8433 & 0.0406 & .84 & $0.8365^{* * *}$ & 0.0407 & .83 \\
\hline Motivators $\times$ success & & & $-0.0583^{* * * * *}$ & 0.0383 & -.07 \\
\hline $\mathrm{R}^{2}$ & 0.71 & & 0.71 & & \\
\hline$\Delta \mathrm{R}^{2}$ & - & & 0.00 & \\
\hline $\mathrm{F}$ & $216.20^{* * *}$ & & & \\
\hline
\end{tabular}

Notes: $\mathrm{B}=$ unstandardized coefficients; $\mathrm{SE}=$ standard errors; $\beta=$ standardised coefficients; $N=187$; ${ }^{* * *}=p<.01 ;{ }^{* *}=p<.05 ;{ }^{*}=p<.10 ; * * * *=p>0.05 ; * * * * *=p>.10$.

An analysis of the results detailed in Table 3 reveal a non-significant $p$-value $(p=0.164)$ for the independent variable 'motivators'. Similarly, the new interaction variable 'motivators $\mathrm{x}$ success' has a non-significant $\mathrm{p}$-value $(p=0.129)$. The results indicate that the beta coefficients for the moderator and the interaction variable are not statistically different from zero, which means that there is insufficient evidence to support hypothesis $5 \mathrm{~b}$.

\section{Discussion}

Since existing work has not yielded generalizable knowledge pertaining to the fundamental nature of OPR in a CE context, by contributing to the innovation literature, this article provides empirical evidence on the frequency and importance of OPR and OPM. Additionally, with reference to perceived success of the CE initiative moderating 
the relationship between frequency of OPR, and perceptions of the importance of OPM, significant results emerge.

Support was found for hypothesis 1 . This positive result is in line with research that finds that the process of opportunity recognition starts with the sensing of a need or a possibility for change and action and ends with an innovative solution in which future potential economic value is clear enough and externally recognised (Ardichvili et al. 2003). Similarly, support was found for hypothesis 2, which resonates with Allen et al. (1997) who suggest that participants join CE programs when it is beneficial and not harmful to their interests, where personal and organisational rewards are often the motivator for joining. Moreover, the support for hypothesis 3 and 4 confirms that the recognition of opportunities includes a set of choices that equates to the execution of CE strategy (Haynie, Sheperd 2009). This set of choices includes deciding the best strategy for exploiting the opportunity given the characteristics of the opportunity and the nature of the environment (Casson 2005). In the light of these analyses it appears that perceived success of the CE initiative moderates the relationship between the frequencies of OPR, providing support for hypothesis 5a. This positive finding indicates that expected CE success gauges participation, where resource availability, a supportive organisational structure, and a culture that is tolerant of failure, are all indicators that success is highly probable (Ireland et al. 2009).

A unique contribution of this study reveals how the moderation effect of OPR varies with the number of opportunities recognised. Recalling that measures in this study were formulated to reflect the role of perceived opportunity attractiveness and motivation when recognising any number of opportunities, it is possible that certain OPR and motivators help reduce the liability of newness and improve the chances for success. Failures and false starts are a normal part of the opportunity recognition process, and the knowledge gained from such experiences often leads to future gains that are more solid. This tendency is reflected in the study results where employees were likely to recognise a higher number of opportunities as more opportunities were perceived to be successfully implemented. Corporate environments supportive of entrepreneurship must provide appropriate reward systems, top management support, explicit goals and appropriate organizational values which signal to employees that entrepreneurial behaviour action is desirable.

\section{Conclusions}

A deep and thorough understanding of opportunity recognition in the CE context is important not only for academic purposes but also because the subject has salience for practitioners and policy makers. These implications relate to the profitability and competitiveness of the firm as well as to the overall economic performance of industry and the national economy. This type of research is also timely and relevant considering that for businesses based in emerging markets the challenge to participate in the global economy of the 21 st century will be to compete as world-class businesses where the focus is on high-value added human capital based on creativity and opportunity recognition leading to high-growth firms. The empirical findings contribute to existing studies where 
evidence of employees developing new business activities at the firm level, suggest that a tentative positive correlation between intrapreneurship and GDP per capita is possible. Thus, it appears that entrepreneurial activities by employees are, as predicted by theory, more prevalent in the more advanced phases of economic development.

Although the study has several limitations it presents future research avenues. The cross-sectional nature of the study prevents any causal relationship between OPR and OPM and CE success to be drawn. A longitudinal study is required to provide further insights and causal inferences into the relationship between OPR and CE success. Modest findings to support the hypotheses may also be related to the influence of other contingencies not incorporated or to measurement issues. Moreover, the study relies on perceptual data where responses may have been influenced by perceptual biases and cognitive limitations. Future studies could investigate in detail the nature of opportunities pursued, and not simply report on the number of opportunities, which could add significantly to understanding OPR and OPM in the CE context. A further avenue for research could be to examine if corporate entrepreneurs use similar creative processes and cognitions to novice entrepreneurs. Another potential research area could focus on the relevance of both individual and institutional network structures in OPR. In general developing a deeper understanding of the complexities of the individual and the situation associated with OPR and OPM represents a fruitful area for advancing research.

\section{References}

Allen, R. E.; Lucero, M. A.; Van Norman, K. L. 1997. An examination of the individual's decision to participate in an employee involvement program, Group Organizational Management 22: 117-131. http://dx.doi.org/10.1177/1059601197221008

Antoncic, B.; Hisrich, R. D. 2001. Intrapreneurship: construct refinement and cross-cultural validation, Journal of Business Venturing 16(5): 495-527.

http://dx.doi.org/10.1016/S0883-9026(99)00054-3

Antoncic, B.; Hisrich, R. D. 2004. Corporate entrepreneurship contingencies and organisational wealth creation, Journal of Management Development 23(6): 518-550.

http://dx.doi.org/10.1108/02621710410541114

Ardichvili, A.; Cardozo, R.; Ray, S. 2003. A theory of entrepreneurial opportunity identification and development, Journal of Business Venturing 18: 105-123.

http://dx.doi.org/10.1016/S0883-9026(01)00068-4

Armstrong, J. S.; Overton, T. S. 1977. Estimating non-response bias in mail surveys, Journal of Marketing Research 14: 396-402. http://dx.doi.org/10.2307/3150783

Bosma, N.; Stam, E.; Wennekers, S. 2010. Intrapreneurship - an international study, EIM Research Report Intrapreneurship. Dutch Ministry of Economic Affairs: Netherlands.

Bruton, G. D.; Ahstrom, D.; Obloj, K. 2008. Entrepreneurship in emerging economies: where are we today and where should the research go in the future, Entrepreneurship Theory and Practice January: 1-14.

Carmody, P. 2012. Another BRIC in the wall? South Africa's developmental impact and contradictory rise in Africa and beyond, European Journal of Development Research 24(2): 223-241. http://dx.doi.org/10.1057/ejdr.2012.8

Casson, M. 2005. The individual - opportunity nexus: a review of Scott Shane: a general theory of entrepreneurship, Small Business Economics 24: 423-430.

http://dx.doi.org/10.1007/s11187-004-5613-x 
Cohen, B.; Winn, M. I. 2007. Market imperfections, opportunity and sustainable entrepreneurship, Journal of Business Venturing 22: 29-49. http://dx.doi.org/10.1016/j.jbusvent.2004.12.001 Cooper, D. R.; Emory, C.W. 1995. Business Research Methods. Chicago: Irwin.

Covin, J. G.; Kuratko, D. F. 2008. The concept of corporate entrepreneurship, in V. Narayanan, G. O'Connor (Eds.). The Blackwell encyclopaedia of technology and innovation management. Oxford: UK, Blackwell Publishers, 32-46.

Covin, J. G.; Slevin, D. P. 1989. Strategic planning of small firms in hostile and benign environments, Strategic Management Journal 10: 75-87. http://dx.doi.org/10.1002/smj.4250100107

Davidsson, P. 2004. Researching entrepreneurship. International studies in entrepreneurship. New York: Springer.

Dess, G. G.; Ireland, R. D.; Zahra, S. A.; Floyd, S. W.; Janney, J. J.; Lane, P. J. 2003. Emerging issues in corporate entrepreneurship, Journal of Management 29(3): 351-378.

Dess, G. G.; Lumpkin, G. T.; McGee, J. E. 1999. Linking corporate entrepreneurship to strategy, structure, and process: suggested research directions, Entrepreneurship Theory and Practice 23: $85-101$.

Dimov, D. 2007. Beyond the single-person single-insight attribution in understanding entrepreneurial opportunities, Entrepreneurship Theory and Practice 31: 713-731.

http://dx.doi.org/10.1111/j.1540-6520.2007.00196.x

Douglas, E. J.; Shepherd, D. A. 2002. Self-employment as a career choice: attitudes, entrepreneurial intentions, and utility maximization, Entrepreneurship Theory and Practice 26: 81-91.

Drucker, P. 1979. The practice of management. London: Pan Books Ltd.

Dysvik, A.; Kuvaal, B. 2011. Intrinsic motivation as a moderator on the relationship between perceived job autonomy and work performance, European Journal of Work and Organisational Psychology 20(3): 367-387. http://dx.doi.org/10.1080/13594321003590630

Financial Services Board. 2011. Financial advisory and intermediate services, approved financial services providers [online], [cited 6 January 2011]. Available from Internet: http://www.fsb.co.za/ Fais/Search_FSP.html

Goedhuys, M.; Sleuwaegen, L. 2010. High-growth entrepreneurial firms in Africa: a quantile regression approach, Small Business Economics 34: 31-51.

http://dx.doi.org/10.1007/s11187-009-9193-7

Government Gazette. 2007. Notice 110 of 2007: Department of Trade and Industry, Financial Sector Charter on Black Economic Empowerment 500(296210): 1-24.

Gregoire, D. A.; Shepherd, D. A.; Lambert, L. S. 2010. Measuring opportunity-recognition beliefs: illustrating and validating an experimental approach, Organizational Research Methods 13: 114-145. http://dx.doi.org/10.1177/1094428109334369

Haynie, M.; Shepherd, D. A. 2009. A measure of adaptive cognition for entrepreneurship research, Entrepreneurship Theory and Practice 33: 695-714.

http://dx.doi.org/10.1111/j.1540-6520.2009.00322.x

Hills, G.; Schrader, R.; Lumpkin, T. 1999. Opportunity recognition as a creative process. Frontiers of Entrepreneurship Research 12: 216-227.

Holmén, M.; Magnusson, M.; McKelvey, M. 2007. What are innovative opportunities?, Industry and Innovation 14(1): 27-45.

Hornsby, J. S.; Kuratko, D. F.; Shepherd, D. A.; Bott, J. P. 2009. Managers corporate entrepreneurial actions: examining perception and position, Journal of Business Venturing 24(3): 236247. http://dx.doi.org/10.1016/j.jbusvent.2008.03.002

Hornsby, J. S.; Kuratko, D. F.; Zahra, S. A. 2002. Middle managers' perception of the internal environment for corporate entrepreneurship: assessing a measurement scale, Journal of Business Venturing 17: 253-273. http://dx.doi.org/10.1016/S0883-9026(00)00059-8 
Hoskisson, R. E.; Eden, L.; Lau, C. M.; Wright, M. 2000. Strategizing in emerging economies, Academy of Management Journal 43: 249-267. http://dx.doi.org/10.2307/1556394

Ireland, R. D.; Covin, J. G.; Kuratko, D. F. 2009. Conceptualizing corporate entrepreneurship strategy, Entrepreneurship Theory and Practice 33(1): 19-46.

http://dx.doi.org/10.1111/j.1540-6520.2008.00279.x

Ireland, R. D.; Webb, J. W. 2007. Strategic entrepreneurship: creating competitive advantage through streams of innovation, Business Horizons 50: 49-59.

Johannesburg Chamber of Commerce and Industry. 2008. Regions, Affiliates and Members JCCI [online], [cited 14 February 2011]. Available from Internet: http://www.jcci.co.za/members/

Kaish, S.; Gilad, B. 1991. Characteristics of opportunities search of entrepreneurs versus executives: sources, interests, and general alertness, Journal of Business Venturing 6: 45-61.

http://dx.doi.org/10.1016/0883-9026(91)90005-X

Kuratko, D. F.; Audretsch, D. B. 2009. Strategic entrepreneurship: exploring different perspectives of an emerging concept, Entrepreneurship Theory and Practice 33(1): 1-17.

http://dx.doi.org/10.1111/j.1540-6520.2008.00278.x

Kuratko, D. F.; Covin, J. G.; Garett, R. P. 2009. Corporate venturing: insights from actual performance, Business Horizons 52: 459-467.

Kuratko, D. F.; Hornsby, J. S.; Naffziger, D. W.; Montangno, R. V. 1993. Implement entrepreneurial thinking in established organizations, SAM Advanced Management Journal 58(1): 28-39. http://dx.doi.org/10.1016/j.bushor.2009.05.001

Lazonick, W. 2008. Entrepreneurial ventures and the developmental state. Lessons from the advanced economies, Discussion Paper No. 2008/01. UNU-WIDER.

Lee, J. H.; Venkataraman, S. 2006. Aspirations, market offerings, and the pursuit of entrepreneurial opportunities, Journal of Business Venturing 21: 107-123.

http://dx.doi.org/10.1016/j.jbusvent.2005.01.002

Lumpkin, G. T.; Hills, G. E.; Shrader, R. C. 2004. Opportunity recognition, in H. Welsch (Ed.). Entrepreneurship: the road ahead. London: Routledge. http://dx.doi.org/10.4324/9780203356821.pt2

Monsen, E.; Patzelt, H.; Saxton, T. 2010. Beyond simple utility: Incentive design and trade-offs for corporate employee-entrepreneurs, Entrepreneurship Theory and Practice 34(1): 105-130. http://dx.doi.org/10.1111/j.1540-6520.2009.00314.x

Morris, M. H.; Kuratko, D. F. 2002. Corporate entrepreneurship. Florida: Harcourt College Publishers.

Morris, M. H.; van Vuuren, J.; Cornwall, J. R.; Scheepers, R. 2009. Properties of balance: a pendulum effect in corporate entrepreneurship, Business Horizons 52(5): 429-440.

http://dx.doi.org/10.1016/j.bushor.2009.04.007

Morrison, D.; Cordery, J.; Girardi, A.; Payne, R. 2005. Job design, opportunities for skill utilization and intrinsic job satisfaction, European Journal of Work and Organisational Psychology 14(1): 59-79. http://dx.doi.org/10.1080/13594320444000272

Neill, S.; York, J. L. 2011. The entrepreneurial perceptions of strategy makers: constructing an exploratory path in the pursuit of radical growth, Journal of Business Research 65(7): 508-515.

Peng, M. W. 2003. Institutional transitions and strategic choices, Academy of Management Review 28: 275-296.

Phan, P. H.; Wright, M.; Ucbasaran, D.; Tan, W. 2009. Corporate entrepreneurship: current research and future directions, Journal of Business Venturing 24: 197-205.

http://dx.doi.org/10.1016/j.jbusvent.2009.01.007

Podsakoff, P.; Mackenzie, S.; Lee, J.; Podsakoff, N. 2003. Common method biases in behavioural research: a critical review of the literature and recommended remedies, Journal of Applied Psychology 88: 879-903. http://dx.doi.org/10.1037/0021-9010.88.5.879 
Poon, J. M.; Ainuddin, R. A.; Junit, S. H. 2006. Effects of self-concept traits and entrepreneurial orientation on firm performance, International Small Business Journal 24: 60-82.

http://dx.doi.org/10.1177/0266242606059779

Roupas, P. 2008. Human and organisational factors affecting technology uptake by industry, Innovation: Management Policy \& Practice 10(1): 4-28.

http://dx.doi.org/10.5172/impp.453.10.1.4

Santangelo, G. D.; Pini, P. 2011. New HRM practices and exploitative innovation: a shop floor level analysis, Industry and Innovation 18(6): 611-630.

http://dx.doi.org/10.1080/13662716.2011.591977

Schumpeter, J. A. 1934. The theory of economic development. Cambridge, MA: Harvard University Press.

Shane, S.; Locke, E. A.; Collins, C. J. 2003. Entrepreneurial motivation, Human Resource Management Review 13: 257-279. http://dx.doi.org/10.1016/S1053-4822(03)00017-2

Tang, L.; Koveos, P. E. 2004. Venture entrepreneurship, innovation entrepreneurship, and economic growth, Journal of Developmental Entrepreneurship 9: 161-171.

Timmons, J. A.; Spinelli, S. 2008. New venture creation. $8^{\text {th }}$ ed. Irwin: McGraw-Hill Higher Education.

Ucbasaran, D.; Westhead, P.; Wright, M. 2009. The extent and nature of opportunity identification by experienced entrepreneurs, Journal of Business Venturing 24: 99-115.

http://dx.doi.org/10.1016/j.jbusvent.2008.01.008

Urban, B. 2009. Opportunity recognition: delineating the process and motivators for serial entrepreneurs, South African Journal of Economic and Management Sciences 12(4): 513-532.

Urban, B. 2013. The importance of attributes in entrepreneurial opportunity evaluations: an emerging market study, Managerial and Decision Economics 35: 523-539.

Wiklund, J. 1999. The sustainability of the entrepreneurial orientation-performance relationship, Entrepreneurship Theory and Practice 24: 37-50.

Yiu, D. W.; Lau, C. M. 2008. Corporate entrepreneurship's resource capital configuration in emerging market firms, Entrepreneurship Theory and Practice (January): 37-57.

Zahra, S. A. 1993. A conceptual model of entrepreneurship as firm behaviour: a critique and extension, Entrepreneurship Theory and Practice 17(4): 5-21.

http://dx.doi.org/10.1016/j.ibusrev.2004.04.005

Zahra, S. A.; Korri, J. S.; Yu, J. 2005. Cognition and international entrepreneurship: implications for research on international opportunity recognition and exploitation, International Business Review 14: 129-146.

Boris URBAN ( $\mathrm{PhD})$ is a Professor and Chair at the University of Witwatersrand and has more than 20 years academic and professional experience in business, where he has practiced, taught and researched strategy, organisational behaviour and entrepreneurship. He is a National Research Foundation rated researcher, and has many scholarly high-impact research publications and is author of the book series: Perspectives in Entrepreneurship: A research companion, published by Pearson.

Eric WOOD is the Executive Director of Regiments Capital. He is considered to be an industry expert in his field and manages an extensive blue chip customer portfolio. He completed his Masters in Management cum-laude and is currently a PhD student at the University of Witwatersrand. His research interests lie in corporate entrepreneurship and venturing. 